\title{
PHENOMENON OF AN ENERGETIC CHARGED PARTICLE EMISSION FROM HYDROGEN/DEUTERIUM LOADED METALS
}

\author{
A.G. LIPSON AND G.H. MILEY \\ Department of Nuclear, Plasma and Radiological Engineering \\ University of Illinois at Urbana-Champaign \\ 103S Goodwin Avenue, Urbana, IL 61801, USA \\ and \\ Russian Academy of Sciences, Institute of Physical Chemistry, 31 Leninsky prospect, \\ Moscow 117915, Russia \\ G.H. MILEY \\ Department of Nuclear, Plasma and Radiological Engineering \\ University of Illinois at Urbana-Champaign, 103S Goodwin Avenue, Urbana, IL 61801, \\ $U S A$
}

\section{A.S. ROUSSETSKI}

Russian Academy of Sciences, Lebedev Physics Institute, 53 Leninsky Prospect, Moscow 117333, Russia

\section{E.I. SAUNIN}

Russian Academy of Sciences, Institute of Physical Chemistry, 31 Leninsky prospect, Moscow 117915, Russia

\begin{abstract}
We report the discovery of the new phenomenon of energetic alpha emission (up to $16.0 \mathrm{MeV})$, and proton emission $(\sim 1.7 \mathrm{MeV})$, from a metal surface possessing a large affinity for hydrogen and loaded/excited by electrolysis, glow discharge or powerful laser. Various experiments on charged particle emission show a remarkable feature: all exhibit a similar yield per unit input energy of energetic alphas [one alpha particle per $10-15 \mathrm{eV}$ input energy/Pd(Ti) target atom], independent of the excitation power of delivering method (electrolysis, glow discharge or laser irradiation). The results suggest that the mechanism of energy transfer resulting in energetic particle emission in metal targets loaded with hydrogen is similar, despite the seemingly dissimilar excitation techniques.
\end{abstract}

\section{Introduction}

Charged particle emission from the surface of $\mathrm{Pd}$ and Ti deuterides has been studied since the beginning of experiments on low energy nuclear reactions (LENR) product detection in metal deuterides. The first charged particle detection experiments were intended primarily to confirm the generation of DD-reaction products $(3.0 \mathrm{MeV}$ protons and $1.0 \mathrm{MeV}$ tritons) in the metal deuteride system. However, along with 


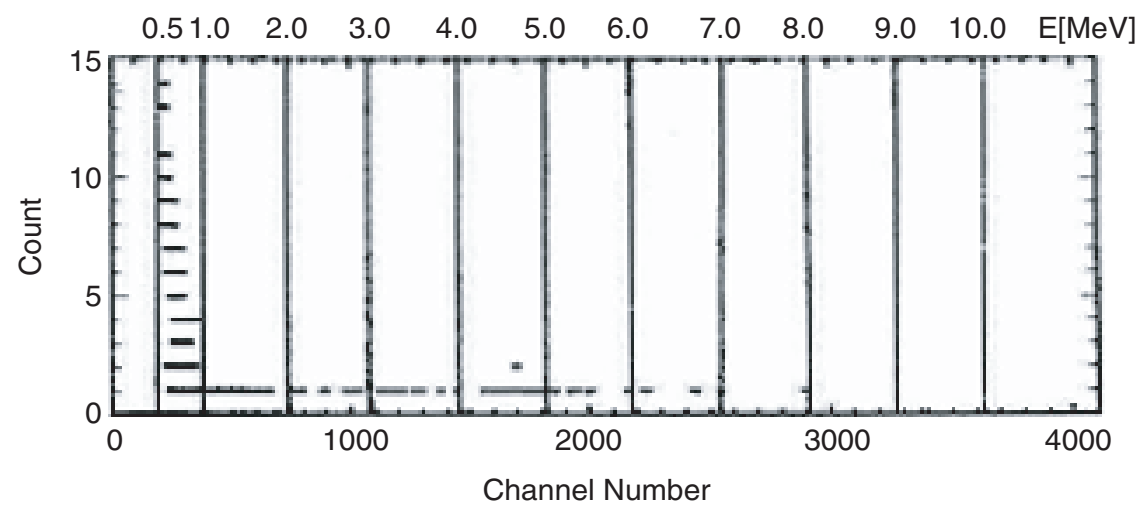

Figure 1. Typical silicon surface barrier detector charged particle spectrum taken over 8 days.

charged DD-reaction products, there appeared reports concerning the detection of more energetic particles than would be expected from DD-reactions, ${ }^{1-4}$ especially during accelerator bombardment of Ti and Pd targets with deuterons at 100-keV.

We reported previously the observation of high energy alpha particle emission in the energy range $8-14 \mathrm{MeV}$ during exothermic deuterium or hydrogen desorption that could not be ascribed to known natural alpha emitters. A typical charged particle spectrum taken in vacuum using an SSB-detector for about 8 days shows no counts beyond an energy of $8.0 \mathrm{MeV}$ (Fig. 1). ${ }^{5}$ This is not surprising since the maximum alpha energy of radon series is about $7.8 \mathrm{MeV}$, while the energy of cosmic ray induced protons rarely exceeds $2.0 \mathrm{MeV}$. In contrast to the background, the $\mathrm{d} E-E$ spectra detected (see Fig. 2) from $\mathrm{Au} / \mathrm{Pd} / \mathrm{PdO}: \mathrm{D}(\mathrm{H})_{x}$ samples during exothermic

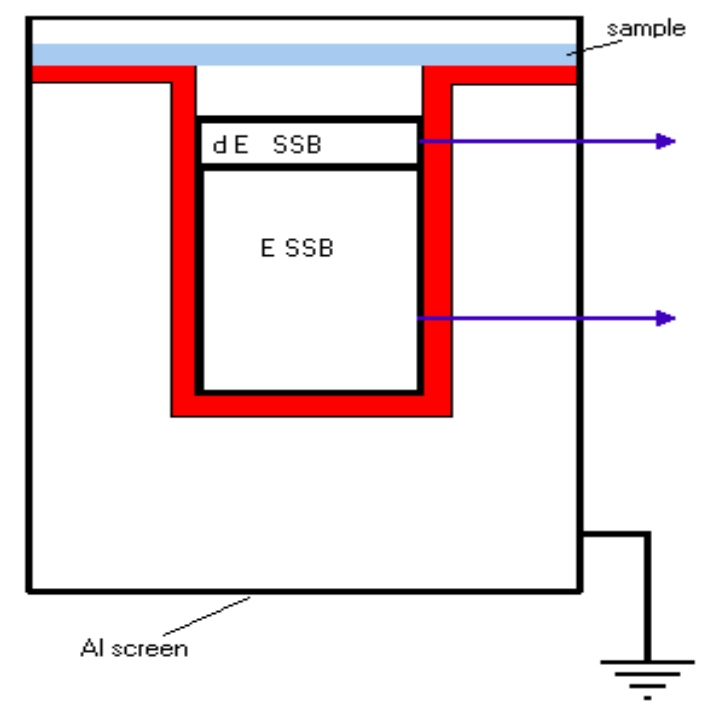

Figure 2. Schematic of experimental arrangement for detection with dE-E detector. 

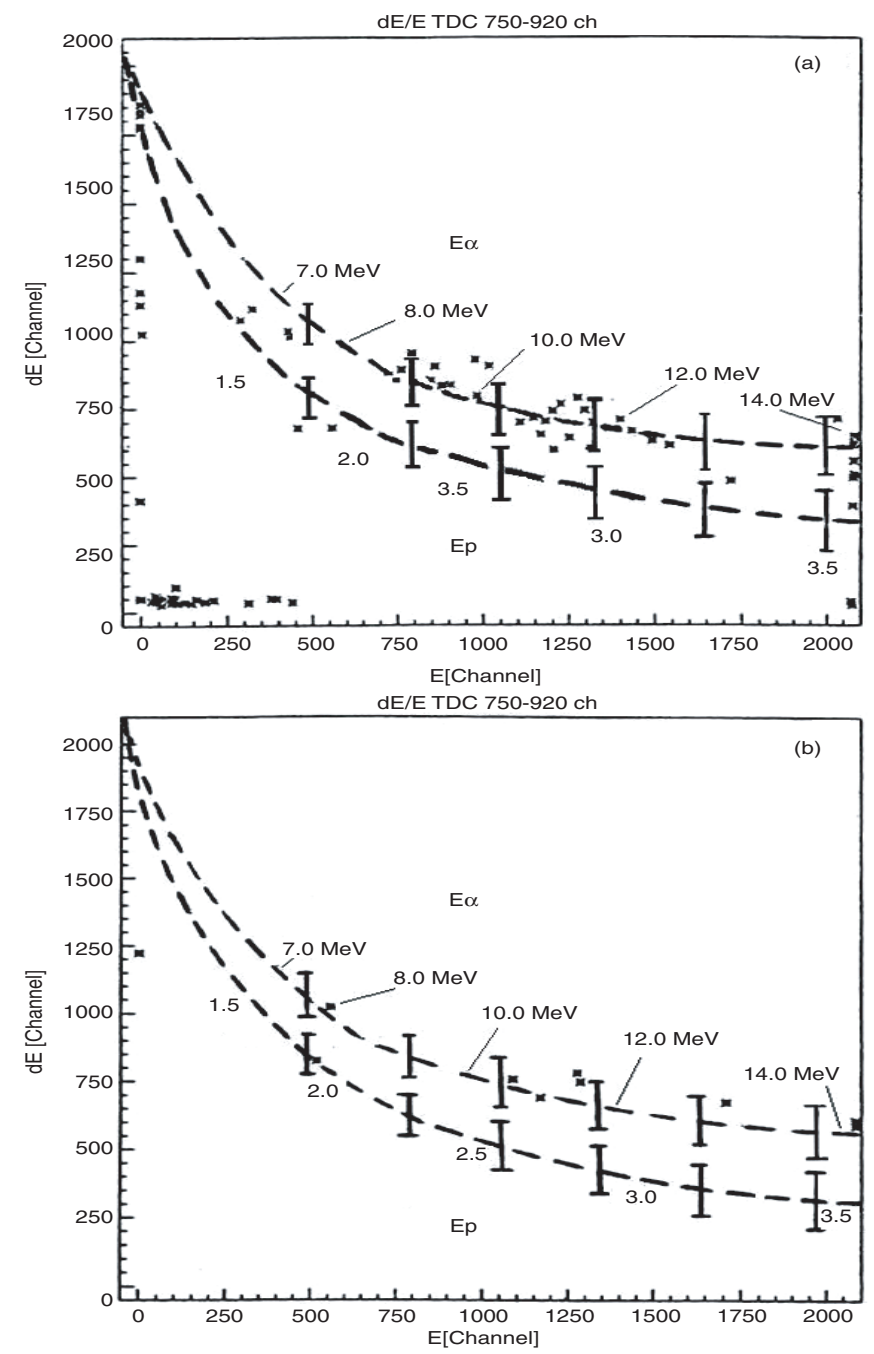

Figure 3. Summary of the results of two-dimensional charged particle spectra obtained with dE-E counter telescope at atmospheric pressure. (a) Au/Pd/PdO:D samples with thickness in the range of $40-60 \mu \mathrm{m}$ (for total exposure time $\sum \tau_{D}=2.0 \times 10^{6} \mathrm{~s}$ ); (b) and for the similar Au/Pd/PdO:H samples $\left(\sum \tau_{H}=4.5 \times 10^{5} \mathrm{~s}\right)$. The broad inclined strip within $200-2000 \mathrm{ch}$ on the $E$ axes and 600 - $1200 \mathrm{ch}$ on $d E$ axes corresponds to alpha particle positions in the energy range $5.5<E_{\alpha}<14.0$ $\mathrm{MeV}$ in accordance with stopping range calculation for Si taking into account $\mathrm{dE}$ and $\mathrm{E}$ detector thickness (dashed line with error bars). The dashed line below alpha-band marks the 1.0-3.5 MeV proton band. The counts that are shown directly at both $\mathrm{E}$ and $\mathrm{dE}$ axes (i.e. one - dimensional) are ascribed to electromagnetic noise or high/low energy cosmic background particles.

deuterium desorption showed clearly the presence of a high energy alpha component (Fig. 3). ${ }^{6}$ New insight was recently obtained from the use of CR-39 track detectors to the study energetic particle emissions from the surface of $\mathrm{Pd} / \mathrm{Ti}$ loaded with hydrogen/deuterium. ${ }^{7}$ Experimental runs with CR-39 to detect long-range alpha particles in situ during electrolysis of $\mathrm{Pd} /$ dielectric substrate cathodes showed en- 

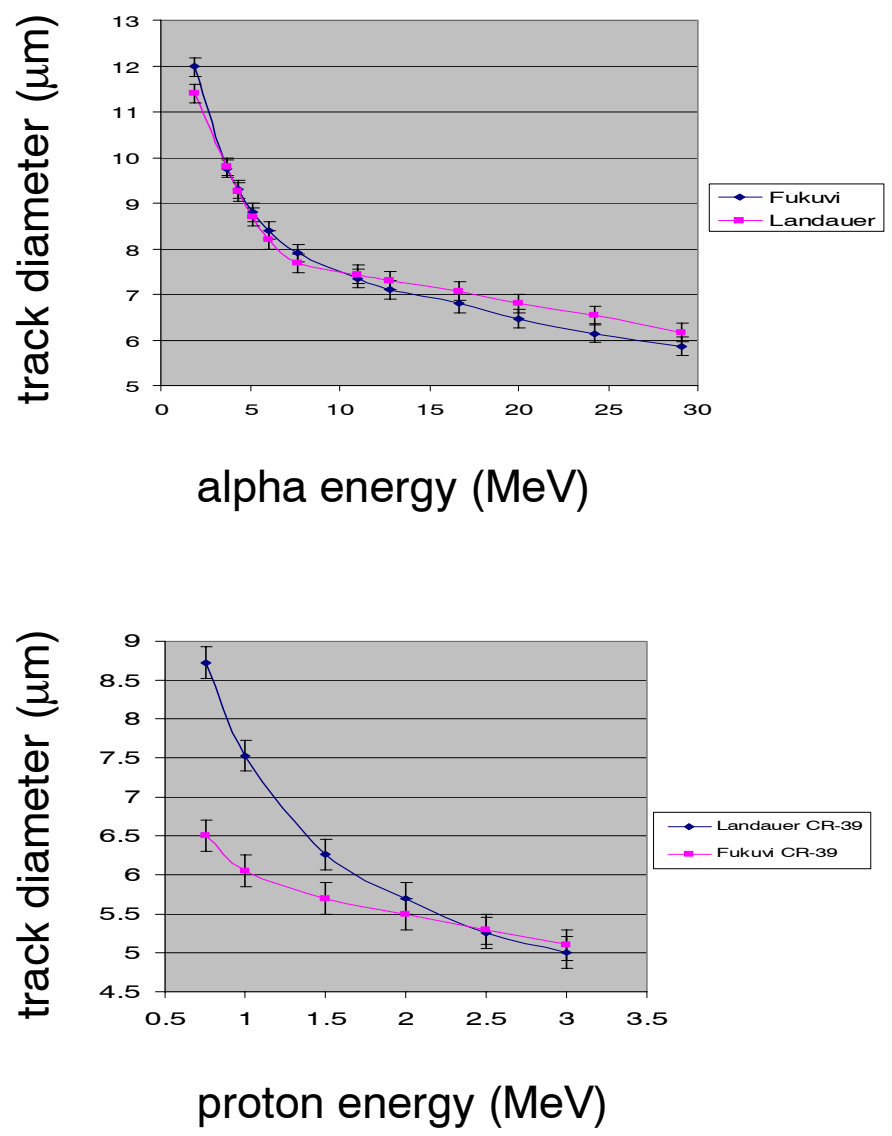

Figure 4. Track diameter for calibration beams versus energy; (top) for alpha particles; and (bottom) for protons. Here and below the Landauer and Fukuvi CR-39 track detectors were etched in $6 \mathrm{~N} \mathrm{NaOH}$ during $7 \mathrm{hr}$.

ergetic alphas $\left(9.0<E_{\alpha}<16.0 \mathrm{MeV}\right)$ with a yield $N_{\alpha} \sim(2-5) \times 10^{-4} \mathrm{~s}^{-1} \mathrm{~cm}^{-2} \mathrm{Pd}$ in $4 \pi$-ster accompanied by an even more intensive emission of $\sim 1.7 \mathrm{MeV}$ protons.

The focus of the present research is the study of energetic charged particle emission at various loadings, and/or excitation, of metals with a large hydrogen/deuterium affinity; and the determination of the yield of energetic charged particle emission, depending on excitation power applied to the sample.

\section{Experimental Technique}

For charged particle detection, we used purified "Radtrack" CR-39 plastic track detectors (of size $2.0 \times 1.0 \mathrm{~cm}^{2}$ ) by Landauer Inc., and Fukuvi Chemical. A special purification procedure utilized in the detector manufacturing, as well as hermetic sealing, allows for the minimization of the initial alpha track density of these CR-39 to less than $20 \mathrm{~cm}^{-2}$. These detectors were calibrated (see Fig. 4) with alpha sources 


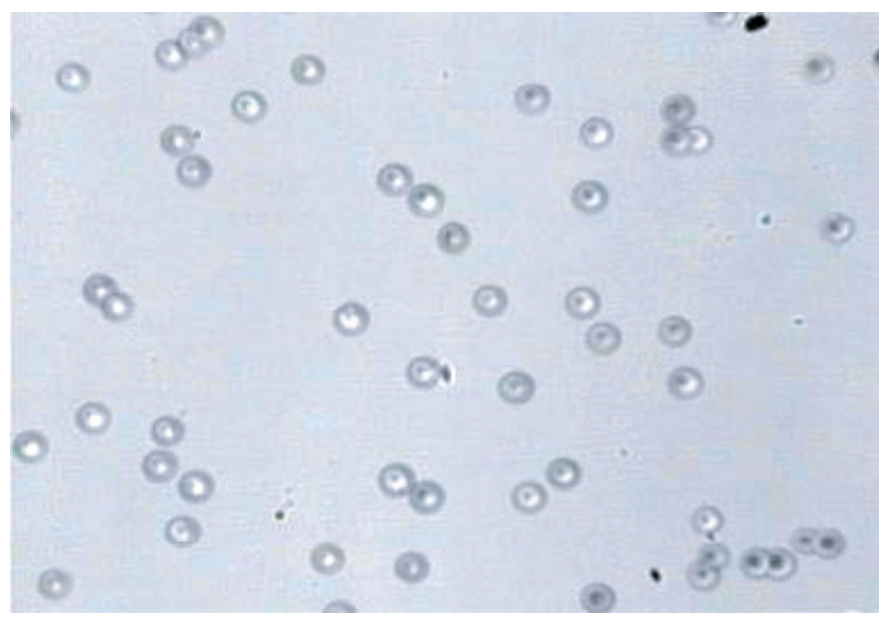

Figure 5. Alpha tracks $(\mathrm{E}=11 \mathrm{MeV})$ at the surface of Landauer CR-39 detector after the etching during $7 \mathrm{hr}$.

(in the range of $1.6-7.7 \mathrm{MeV}$ ), with monoenergetic cyclotron alpha beams (in the energy range of $10.0-30.0 \mathrm{MeV}$ ), and also with proton beams (in the range of 2.0$3.0 \mathrm{MeV}$ ). For energetic proton detection, the detectors were also calibrated using a Van de Graaf accelerator by monoenergetic proton beams (with energy ranging from $0.75 \leq E_{\mathrm{p}} \leq 3.0 \mathrm{MeV}$ ) (Fig. 4). After beam exposure, the CR-39 detectors were etched in $6 \mathrm{~N} \mathrm{NaOH}$ at $t=70^{\circ} \mathrm{C}$ for $7 \mathrm{~h}$, and then inspected with an optical microscope. A typical view of the resulting alpha track picture is shown in Fig. 5 . As can be seen, the tracks observed after the etching have almost ideal circle-like shape at normal incidence. These nuclear tracks can be easily distinguished from defects in the CR-39 subsurface structure.

The efficiency of CR-39 detection with respect to different energy alphas and protons were estimated in accordance with their critical angles $\theta_{c}$, which were determined by formula ${ }^{4}$

$$
\theta_{\mathrm{c}}=\sin ^{-1}\left\{\left[1-\left(d_{E} / 2 h\right)^{2}\right]\left[1+\left(d_{E} / 2 h\right)^{2}\right]\right\}
$$

where $d_{E}$ is the track diameter produced by charged particle with energy $E$ (Figs. 1 and 3), and $h=9$. One micron is the depth of the etched layer in CR-39 under our etching conditions. A knowledge of the critical angles calculated from above formula allow to determine the efficiency $\varepsilon$ of the charged particle detection as

$$
\varepsilon=\frac{1}{2}\left(1-\sin \theta_{c}\right)
$$

In electrolysis experiments, the freshly opened CR-39 detector chips were attached either to the $\mathrm{Pd}$ thin film cathode (foreground), or to the substrate side or/and immersed in electrolyte in the cell (background). Background experiments 


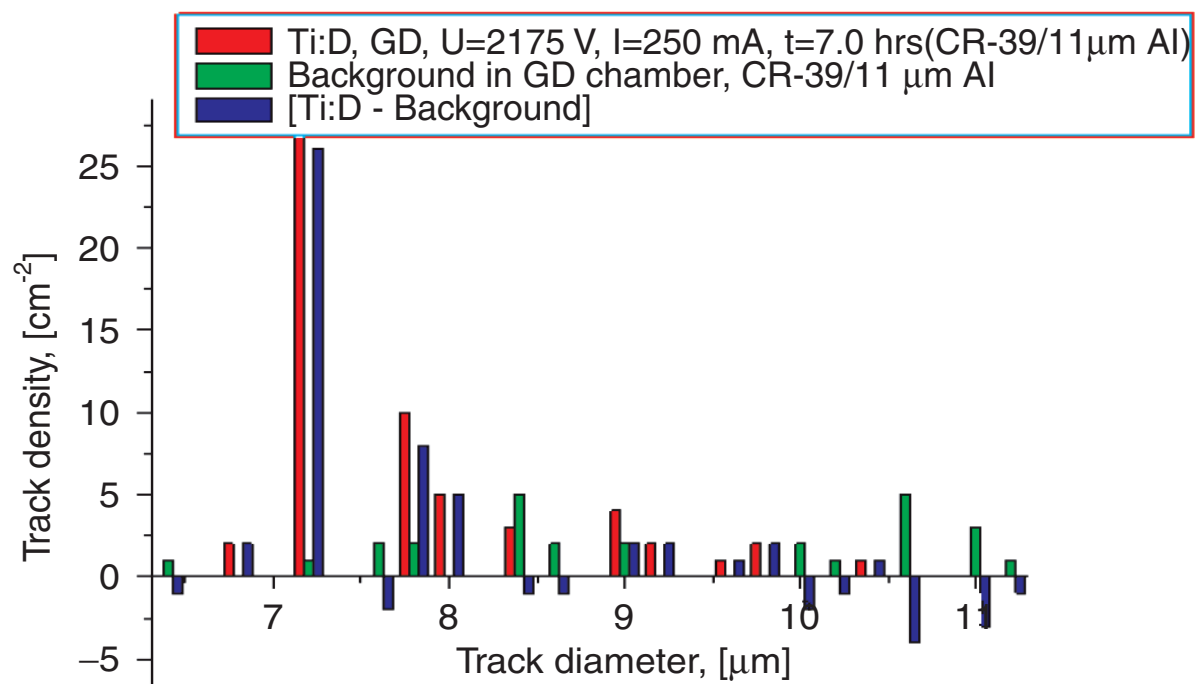

Figure 6. Track density versus track diameter for Fukuvi CR-39 track detectors shielded with 11 $\mu \mathrm{m} \mathrm{Al} \mathrm{film,} \mathrm{and} \mathrm{exposed} \mathrm{in} \mathrm{a} \mathrm{deuterium} \mathrm{glow} \mathrm{discharge} \mathrm{(U=2175} \mathrm{V,} \mathrm{I=250} \mathrm{mA)} \mathrm{for} 7 \mathrm{hr}$.

showed a proportional growth of the track density versus time for CR-39 immersed in the electrolyte (Fig. 5). For large background run time, it is possible to observe two separate alpha peaks with track diameters located at 8.0 and $9.0 \mu \mathrm{m}$, respectively (Fig. 6). The energy positions of these peaks are in good agreement with the conventional alpha background; they correspond to (roughly) $7.0 \mathrm{MeV}$ radon $(8.0 \mu \mathrm{m})$, and $5.0 \mathrm{MeV}(9.0 \mu \mathrm{m})$ thorium, series of natural alpha nuclides.

In order to separate high energy alphas from low energy protons that might be emitted during electrolysis, thin $\mathrm{Cu}$ foils $(25 \mu \mathrm{m}$ thick) were inserted between the cathode metallic coating and the CR-39 detector surface. A $25 \mu \mathrm{m} \mathrm{Cu}$ coating completely absorbs all alpha particles, and protons, with energies below 9.0 and $2.3 \mathrm{MeV}$, respectively. Background measurements in experiments with $\mathrm{Cu}$ covered CR-39 were performed similarly to those done with open detectors. As expected, these background experiments showed a significant reduction ( $\sim 2$ times $)$ in the total track density as compared to those with open CR-39 detectors.

In experiments with the glow discharge, and with laser irradiation, we used CR-39 Fukuvi detectors covered with $\mathrm{Al}$ or $\mathrm{Cu}$ foils (with a thickness in the range of $11-66 \mu \mathrm{m}$, or $25-50 \mu \mathrm{m}$, respectively, for particle identification and energy estimation. The experimental setup used for deuterium glow discharge Ti cathode bombardment, and for powerful picosecond laser irradiation of $\mathrm{Ti}$ and $\mathrm{TiD}_{x}$ targets, are described elsewhere. Power densities applied to the loaded/excited Pd or Ti samples (with respect to the total sample volume) during the electrolysis experiment, in the glow discharge bombardment, and in laser irradiation, are estimated as $(2-5) \times 10^{2}, 10^{5}$ to $10^{6}$ and $\sim 10^{21} \mathrm{~W} / \mathrm{cm}^{3}$, respectively. In a series of experiments with the glow discharge, detectors covered with $11-33 \mu \mathrm{m} \mathrm{Al}$ foils were placed behind holes drilled in a Mo anode at the distance of $3.0 \mathrm{~cm}$ from the Ti 


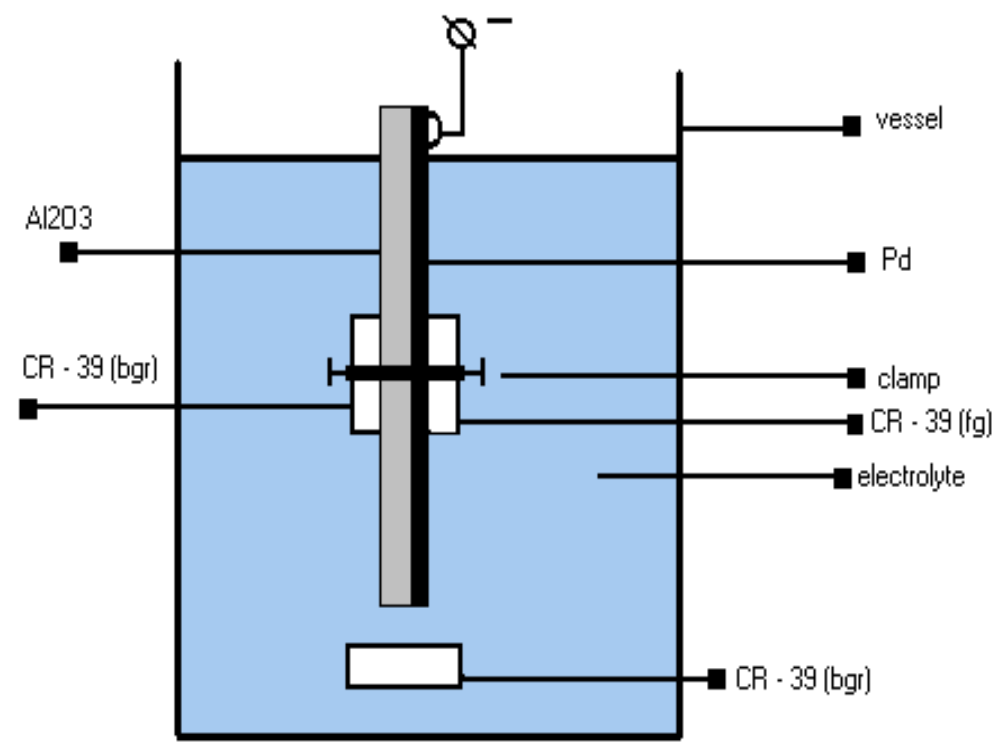

Figure 7. Schematic of charged particle measurements in electrolysis.

cathode surface. In the laser experiment, detectors shielded with 11-66 $\mu \mathrm{m}$ of $\mathrm{Al}$ or $25-50 \mu \mathrm{m}$ of $\mathrm{Cu}$ were placed at different angles toward the target $(20 \mathrm{~cm}$ from the front of the target perpendicular to the beam direction and $4 \mathrm{~cm}$ behind the target). Utilization of shielding foils of various thickness, combined with the CR-39 calibration data, allow us to identify and roughly reconstruct the energy spectra of emitted alpha particles and protons.

\section{Experimental Results: Electrolysis}

In foreground runs with electrolysis of Pd thin film cathodes (see Fig. 7), the exposed CR-39 detectors ( $t \sim 2.0-30$ days) showed unusual diameter tracks that were not observed in background detectors exposed in the same electrolytic cell. Indeed, in the distribution of track diameters $N(d)$, two significant peaks located at 7.0 and $6.0 \mu \mathrm{m}$ are observed in the foreground runs (with electrolysis) with open CR-39 detectors (Fig. 8). At the same time, almost no counts for tracks with $d<7.5 \mu \mathrm{m}$ were found in the corresponding background runs for detectors exposed in the same electrolytic cells. The low diameter tracks appear to accompany the electrolysis of the thin Pd film and Pd black cathodes. The intensity of charged particle emission, and the ratio between 6.0 and $7.0 \mu \mathrm{m}$ peaks during electrolysis, depend strongly on the cathode history and structure (Table 1 ). It should be noted that the generation of charged particle emission during the electrolysis of thin Pd cathodes has good reproducibility (in contrast to the irreproducible emission of DD-products in PdD 


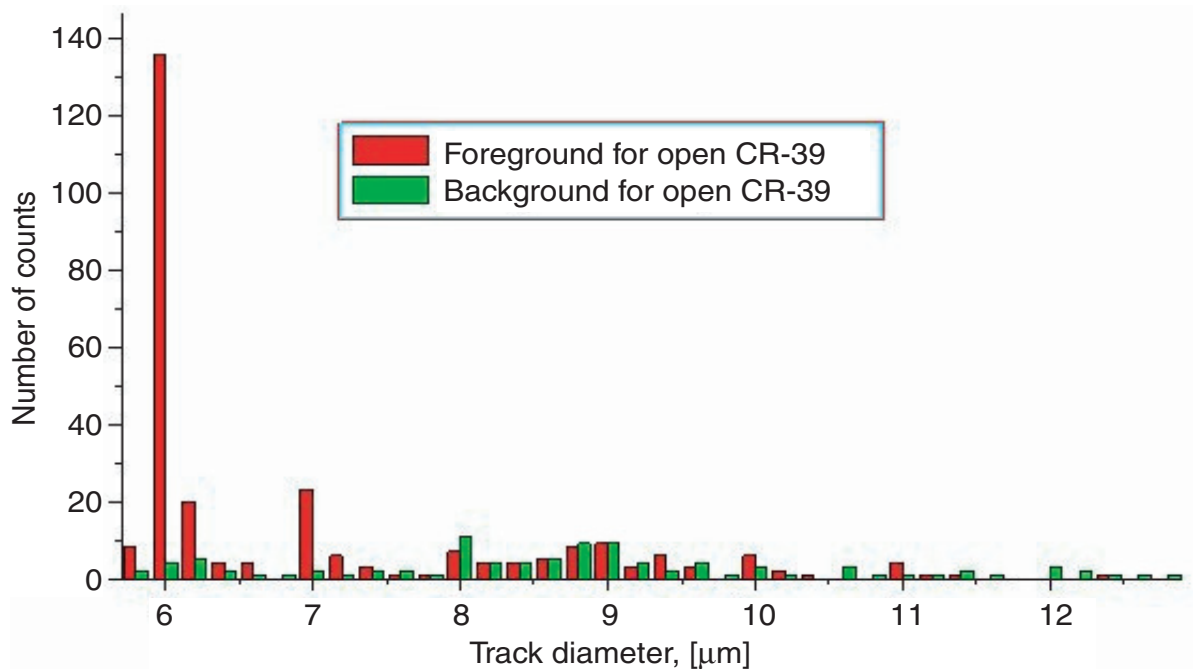

Figure 8. Number of charged particles vs. track diameters for Landauer CR-39 detectors attached to the Pd thin film cathodes (foreground) and to the alumina/glass substrate (background) during electrolysis.

systems).

In foreground runs with the same cathode the 7.0 and $6.0 \mu \mathrm{m}$ peaks disappeared when carried out with $25 \mu \mathrm{m} \mathrm{Cu}$ film shielded CR-39 chips. But other maxima ranging from 7.5 to $11.4 \mu \mathrm{m}$ appeared that were not found in the $\mathrm{Cu}$ shielded background

Table 1. Charged particle (alphas and protons, accordingly to open CR-39 detectors) and x-ray emission with background subtraction during electrolysis of different metal thin film cathodes.

\begin{tabular}{|c|c|c|c|c|c|}
\hline sample: & $\mathrm{A}$ & $\mathrm{B}$ & $\mathrm{C}$ & $\mathrm{D}$ & $\mathrm{E}$ \\
\hline $\begin{array}{l}\text { exposure } \\
\text { (hrs) }\end{array}$ & 48 & 118 & 216 & 802 & 118 \\
\hline $\begin{array}{l}\text { sample } \\
\text { history }\end{array}$ & $\begin{array}{l}\text { Pd coating } \\
\text { fractured } \\
\text { completely } \\
\text { for } 24 \mathrm{hrs}\end{array}$ & survived & $\begin{array}{l}\text { Pd black } \\
\text { partially } \\
\text { detached }\end{array}$ & survived & $\begin{array}{l}\text { survived, no } \\
\text { electrolysis } \\
\text { at Ni surface }\end{array}$ \\
\hline $\begin{array}{l}\text { excess } \\
\text { heat? }\end{array}$ & none & $E_{e x} \sim 20 \%$ & $E_{e x} \leq 8.0 \%$ & none & none \\
\hline $\begin{array}{l}\left\langle N_{\alpha}\right\rangle \\
\left\langle N_{p}\right\rangle \\
\left\langle N_{p}\right\rangle /\left\langle N_{\alpha}\right\rangle\end{array}$ & $\begin{array}{c}4.8 \pm 1.0 \\
28.6 \pm 4.1 \\
6.0\end{array}$ & $\begin{array}{c}6.9 \pm 1.2 \\
16.0 \pm 0.2 \\
2.3\end{array}$ & $\begin{array}{c}0.80 \pm 0.28 \\
5.8 \pm 0.9 \\
7.2\end{array}$ & $\begin{array}{c}0.18 \pm 0.08 \\
0.24 \pm 0.11 \\
1.5\end{array}$ & $\begin{array}{l}0.0 \\
0.0 \\
-\end{array}$ \\
\hline $\mathrm{x}$-ray dose & $\begin{array}{c}\mathrm{LiF} 2.0 \pm 1.0 \\
\mathrm{Al}_{2} \mathrm{O}_{3}: \mathrm{C} 0.5 \pm 0.5\end{array}$ & $\begin{array}{l}\mathrm{Al}_{2} \mathrm{O}_{3}: \mathrm{C} \\
0.2 \pm 1.0\end{array}$ & $\begin{array}{c}\text { not } \\
\text { measured }\end{array}$ & $\begin{array}{c}\text { not } \\
\text { measured }\end{array}$ & $\begin{array}{l}\mathrm{Al}_{2} \mathrm{O}_{3}: \mathrm{C} \\
0.1 \pm 1.0\end{array}$ \\
\hline
\end{tabular}




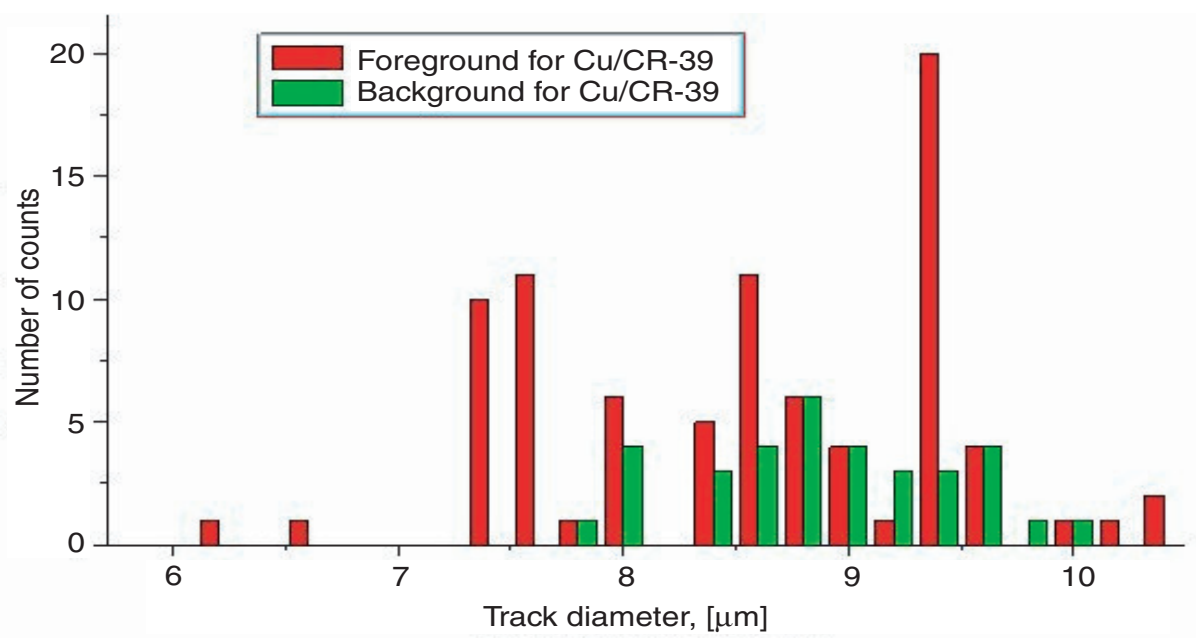

Figure 9. The same as in Fig. 8, but with Landauer CR-39 shielded with a $25 \mu \mathrm{m} \mathrm{Cu}$ film.

detectors (Fig. 9). As remarked above, results obtained with shielded detectors allow us to make particle identifications. Taking into account stopping power of $25 \mu \mathrm{m}$ $\mathrm{Cu}$ film, and the ranges of alpha particles and protons with different energies, the initial energies of emitted particles were also calculated. A comparison of pictures obtained with open and shielded detectors shows that the $6 \mu \mathrm{m}$ peak has completely disappeared, while the broad peak near $7.0 \mu \mathrm{m}$ peak in Fig. 8 has shifted to larger

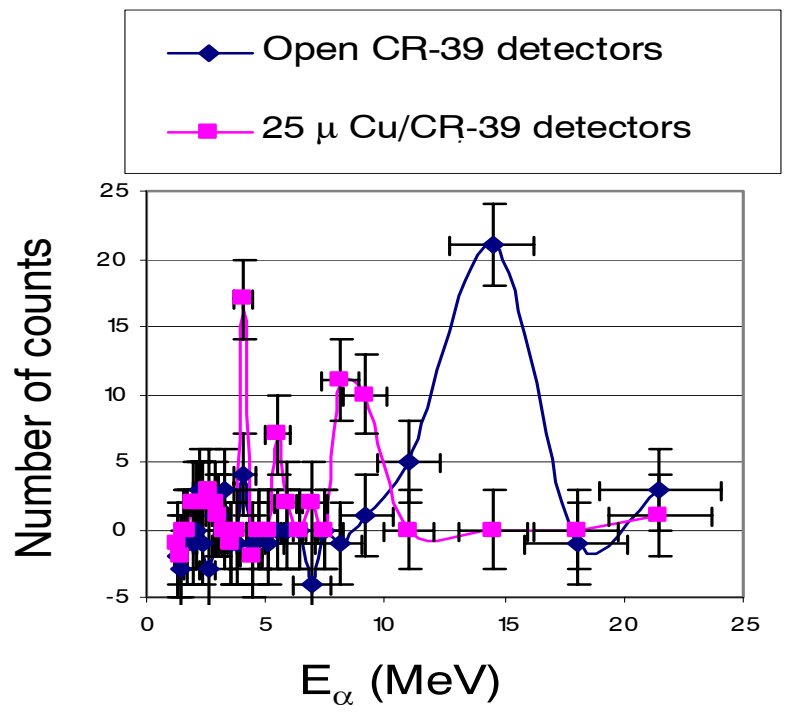

Figure 10. Reconstructed spectra of alpha particles (after background subtraction) deduced from the data obtained during electrolysis with open and $\mathrm{Cu}$ shielded CR-39 detectors $\left(3.0 \mathrm{~cm}^{2}\right)$ attached to the Pd cathode. 


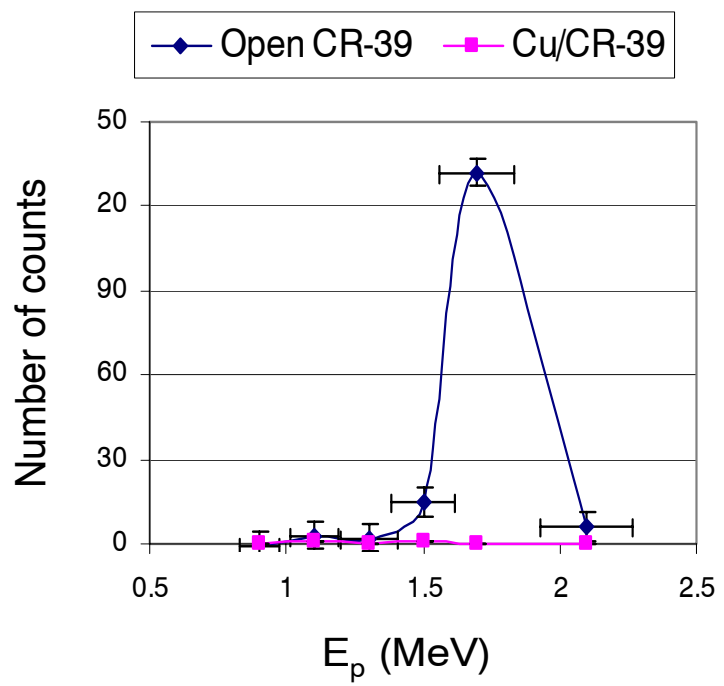

Figure 11. Reconstructed spectra of protons deduced from the data obtained during electrolysis with open and $\mathrm{Cu}$-shielded CR-39 detectors $\left(3.0 \mathrm{~cm}^{2}\right)$ attached to the Pd cathode.

track diameters, and has split into at least three narrow peaks (Fig. 9). The disappearance of the $6.0 \mu \mathrm{m}$ peak in a shielded detector indicates that this peak is due to low $\mathrm{MeV}$ protons. In accordance with our calibration data, the estimated proton energy would be within $1.5-1.7 \mathrm{MeV}$ (Fig. 10 and in Fig. 11). ${ }^{7}$

In contrast to the $6.0 \mu \mathrm{m}$ peak, the $7.0 \mu \mathrm{m}$ maximum should be ascribed to a broad $11-16 \mathrm{MeV}$ alpha peak, due to its shift and splitting after crossing the $\mathrm{Cu}$ shield. Indeed, the stopping range of alphas ranging from 11 to $16 \mathrm{MeV}$ (for open Cr-39) would be consistent with observed narrow bands with energies 11.6, 12.5 and $14-16 \mathrm{MeV}$, respectively, for the $\mathrm{Cu}$ covered detectors (Fig. 10). Due to the higher resolution of CR-39 alpha tracks for the lower energy particles (Fig. 1), the broad $11-16 \mathrm{MeV}$ alpha band could be observed as the single individual maxima after these particles crossed the $\mathrm{Cu}$ foil.

Consequently, we have shown that electrochemical loading of $\mathrm{Pd}$ thin film cathodes on dielectric substrates unambiguously produce high energy charged particles: $1.5-1.7 \mathrm{MeV}$ protons and $11-16 \mathrm{MeV}$ alphas.

\section{Experimental Results: Glow Discharge}

Let us consider in detail the new results on energetic charged particle emission obtained using a more powerful loading process during low energy deuteron bombardment of a titanium cathode in a glow discharge (see Fig. 12). Typical spectra of charged particles emitted in such an experiment obtained with $11 \mu \mathrm{m}$ and $33 \mu \mathrm{m}$ shielded CR-39 detectors are shown in Fig. 13. As can be seen, the spectrum of charged particles of $11 \mu \mathrm{m}$ shielded CR-39 contains three characteristic peaks with track diameters $5.2,6.2$, and $7.2 \mu \mathrm{m}$, respectively. In accordance with the 


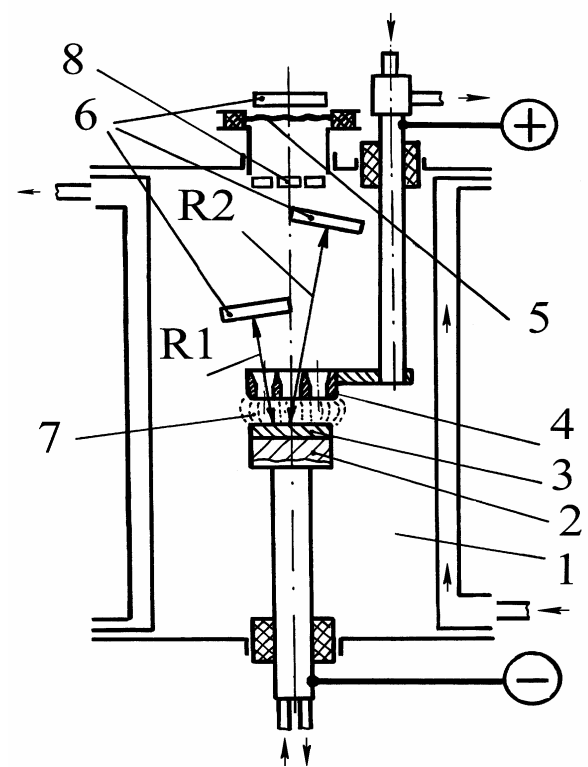

Figure 12. Glow discharge set up with CR-39 detectors (6). Indicated in this figure is the cathode sample (3), the anode (4), and discharge (7).

Fukuvi Cr-39 calibration, these peaks can correspond to $3.0 \mathrm{MeV}$ protons $(5.2 \mu \mathrm{m})$, $1.4 / 2.8 \mathrm{MeV}$ protons/deuterons $(6.2 \mu \mathrm{m})$ and $13.0 \pm 2.0 \mathrm{MeV}$ alphas $(7.2 \mu \mathrm{m})$. An increase in the $\mathrm{Al}$ shielding thickness from 11 to $33 \mu \mathrm{m}$ leads to a corresponding increase in the track diameters for all three peaks observed with the $11 \mu \mathrm{m}$ Al-covered Cr-39 detectors. The shifts of these peaks $(5.2 \rightarrow 5.6 \mu \mathrm{m} ; 6.2 \rightarrow 6.6+6.8 \mu \mathrm{m}$ (spit-

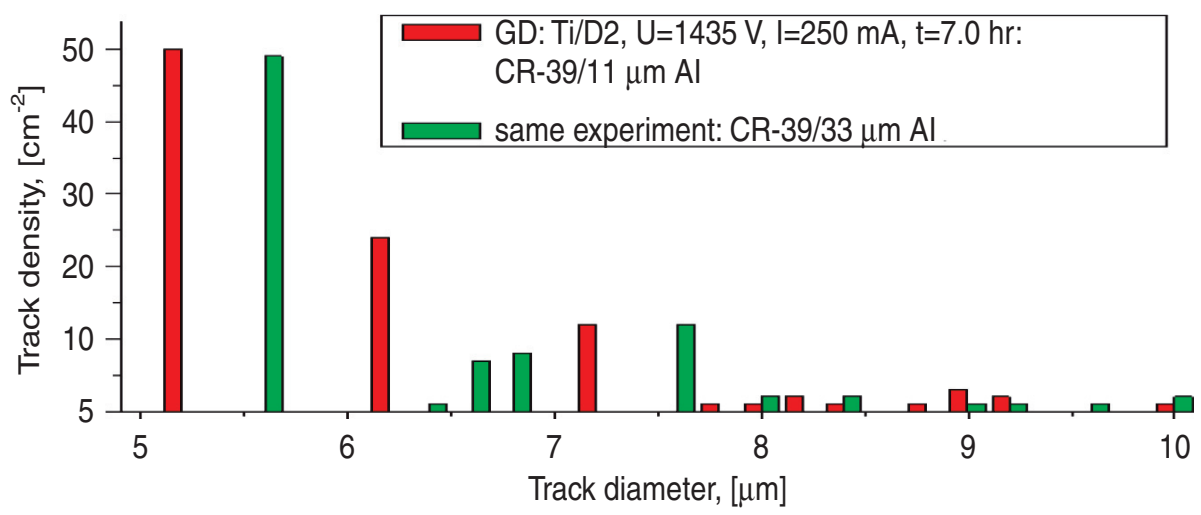

Figure 13. Track density versus track diameter obtained during $7 \mathrm{~h}$ in a deuterium pulsed glow discharge experiment ( $\mathrm{Ti}$ cathode, $\mathrm{U}=1435 \mathrm{~V}, \mathrm{I}=250 \mathrm{~mA}$, pulse duration $=200 \mathrm{~s},=2 \mathrm{kHz}$ ) with 11 and $33 \mathrm{~m} \mathrm{Al}$ shielded CR-39 Fukuvi Chemical detectors. The shifts in peak positions with increase in shielding thickness correspond to $3 \mathrm{MeV}$ protons $(5.2 \rightarrow 5.6 \mu \mathrm{m}), \quad 2.8 \mathrm{MeV}$ deuterons $(6.2 \rightarrow 6.6+6.8 \mu \mathrm{m})$ and $13.0 \mathrm{MeV}$ alphas $(7.2 \rightarrow 7.6 \mu \mathrm{m})$ accordingly to stopping ranges of these particles. 


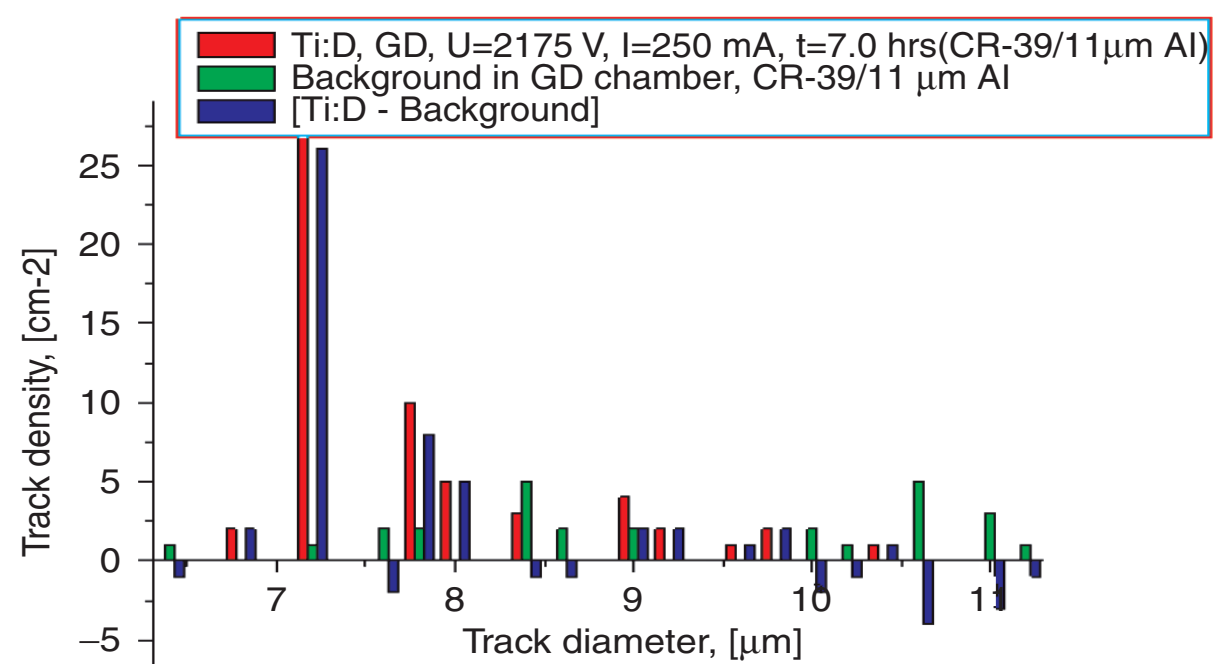

Figure 14. Track density vs. track diameter for Fukuvi CR-39 track detectors shielded with 11 $\mu \mathrm{m} \mathrm{Al} \mathrm{film} \mathrm{and} \mathrm{exposed} \mathrm{in} \mathrm{glow} \mathrm{discharge} \mathrm{in} \mathrm{deuterium}(\mathrm{U}=2175 \mathrm{~V}, \mathrm{I}=250 \mathrm{~mA})$ during $7 \mathrm{hr}$ and at the wall of discharge chamber (background).

ting) and $7.2 \rightarrow 7.6 \mu \mathrm{m}$ ) correspond to energy losses of $3.0 \mathrm{MeV}$ protons (from DD-reaction), $2.8 \mathrm{MeV}$ deuterons, and $13.0 \mathrm{MeV}$ alphas, in accordance with the stopping ranges of these energetic particles in Al. In Fig. 14, the more detailed picture of alpha emission is presented and compared to the background in glow discharge chamber.

As can be seen in Fig. 14, the energetic alpha emission in the glow discharge (at the given discharge parameters) exceeds the background in the range of $7.2 \mu \mathrm{m}$ track diameters by about 25 times. At the same time, the usual alpha background $(d \geq 8.0 \mu \mathrm{m})$ in the presence of the glow discharge is not significantly different from that in absence of glow discharge voltage. The yield of energetic alphas after background subtraction was found to be $N_{\alpha}=0.12 \pm 0.02$ alphas $/ \mathrm{s}$ in $4 \pi$-ster. This yield of energetic alphas is about two to three orders of magnitude higher than that detected in the electrolysis experiment. The yield of $2.8 \mathrm{MeV}$ deuterons in the glow discharge experiment is about two to three times larger than for alphas.

In Fig. 15, the charged particle spectra obtained for two different glow discharge voltages are presented. As is expected, the $3.0 \mathrm{MeV}$ peak from the DD-reaction in Ti under deuteron bombardment depends strongly on the glow discharge voltage. Meanwhile, the intensities of $2.8 \mathrm{MeV}$ deuteron and $13 \mathrm{MeV}$ alpha peaks have a much weaker dependence on the glow discharge voltage. The dependence of $3.0 \mathrm{MeV}$ protons, $2.8 \mathrm{MeV}$ deuterons and $13.0 \mathrm{MeV}$ alphas on the discharge voltage (in the range of $0.8-2.45 \mathrm{kV}$ ) are presented in Figures 16 and 17. These results show this much weaker dependence, which indicates an absence of a direct connection between energetic charged particle emission and DD-reactions. As can be seen in Figures 16 and 17 , the yields of energetic deuterons and alpha particles normalized to the effec- 


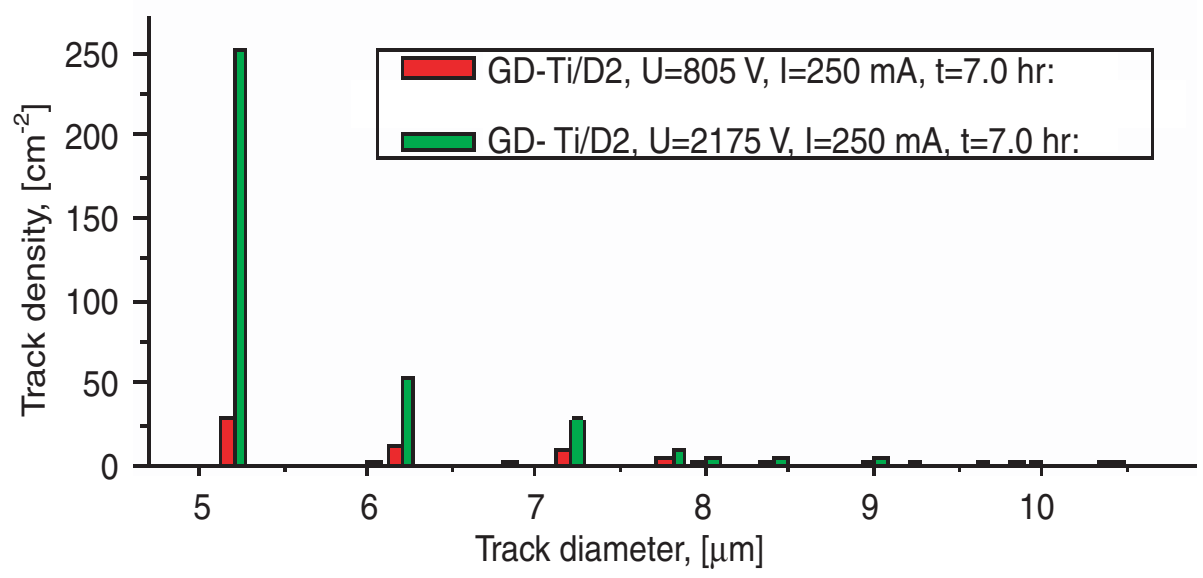

Figure 15. Yields of $3.0 \mathrm{MeV}$ proton, $2.8 \mathrm{MeV}$ deuteron and $13 \mathrm{MeV}$ alpha peaks versus glow discharge voltage illustrated by two measurements at constant current $\mathrm{I}=250 \mathrm{~mA}$ and voltages $\mathrm{U} 1$ $=805 \mathrm{~V}$ and $\mathrm{U} 2=2175 \mathrm{~V}$, respectively.

tive discharge power are almost independent of the deuteron energy $E_{\mathrm{d}}$, while the DD-reaction yield of $3.0 \mathrm{MeV}$ protons tends to grow exponentially with increasing $E_{\mathrm{d}}$.

The yields of energetic deuterons and alpha particles in the glow discharge are roughly proportional to the glow discharge power applied to the Ti cathode (Fig. 18). The fact of near linear dependence of energetic charged particle emission yields on

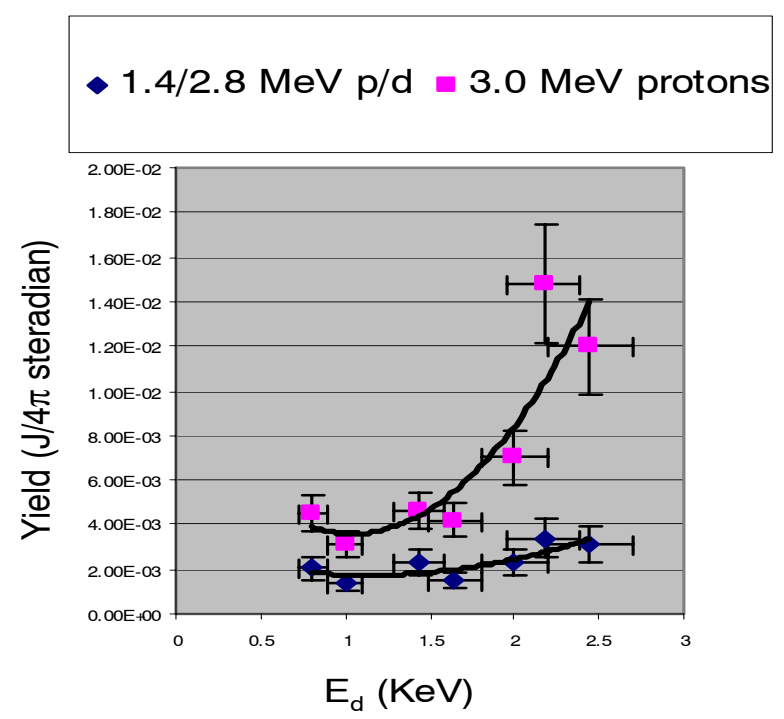

Figure 16. The yields of $3 \mathrm{MeV}$ protons (from DD-reactions in the titanium cathode) and 2.8 $\mathrm{MeV}$ deuterons as a function of the incident deuteron energy in the glow discharge, normalized to the effective discharge power. 


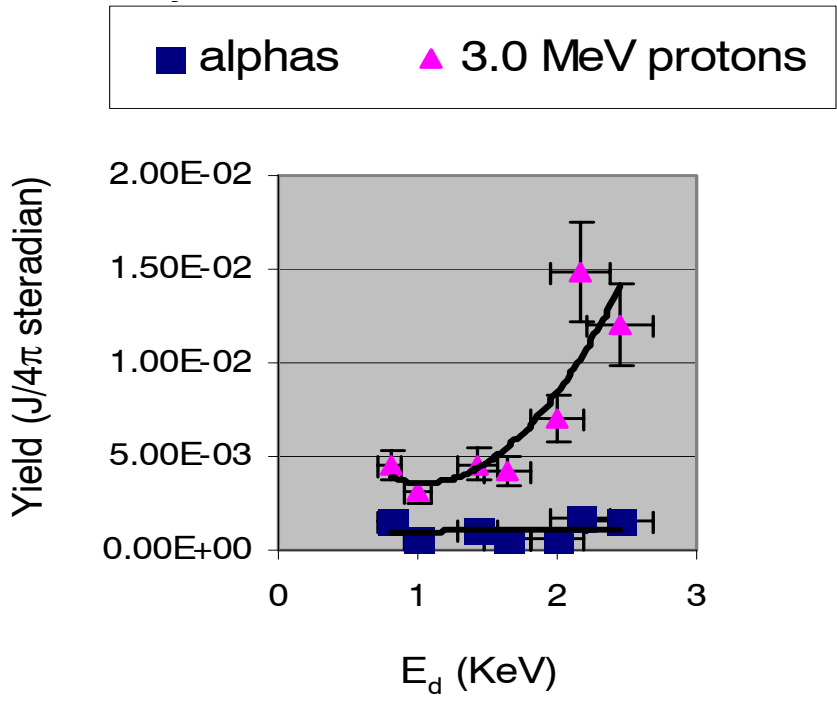

Figure 17. The yields of $3 \mathrm{MeV}$ protons from DD-reaction in Ti cathode and energetic alphas versus deuteron energy in glow discharge normalized to the effective discharge power.

effective power applied to the $\mathrm{Ti}$ cathode leads to a simple assumption that the yield of energetic charged particle emission from the surface of metals with large affinity to hydrogen could be further increase with increase in specific power applied to these metals.

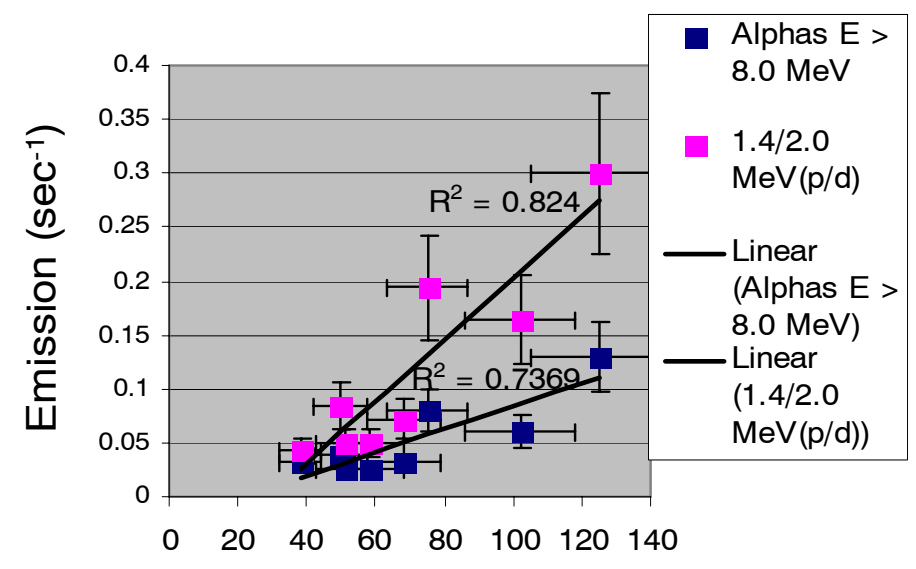

Applied power (W)

Figure 18. The emission ( $\mathrm{sec}^{-1}$ (yields) of $2.8 \mathrm{MeV}$ deuterons and energetic alphas versus glow discharge power. 


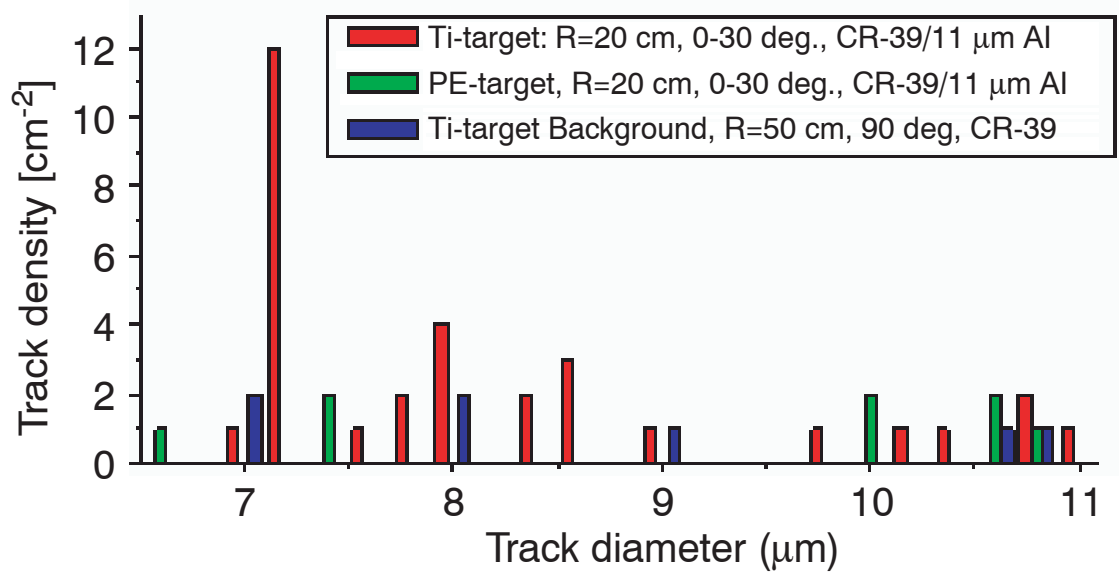

Figure 19. Track density vs. track diameter obtained in laser experiment with Ti and Polyethylene targets and in Background measurement in the chamber. CR-39 detectors (Fukuvi Chemical) shielded with $11 \mu \mathrm{m} \mathrm{Al}$ foil.

\section{Experimental Results: Laser Experiment}

To check the assumption that the yield of energetic charged particles increases with applied specific power, we have performed a search of energetic alphas in experiments with high intensity picosecond laser exciation of $\mathrm{Ti} / \mathrm{TiH}_{x}$ and $\mathrm{TiD}_{x}$ targets. The details of these experiments (including the experimental set up) are described in another paper published in this proceedings. ${ }^{8}$ We note here that intense laser irradiation of solid targets (polymers and some metals including $\mathrm{Al}, \mathrm{Pb} \mathrm{LiD}$, etc.) was studied during last 10 years to induce intense $\mathrm{MeV}$ protons and heavy ion emission, as well as for the purpose of inertial DD-fusion and isotope separation (see review article). ${ }^{9}$ Here, in experiments with an intense laser we first use targets possessing a large affinity for hydrogen/deuterium ( $\mathrm{Ti}$ and $\mathrm{TiD}_{x}$ foils of $30 \mu \mathrm{m}$ thick). The laser parameters were: power density $P=2 \times 10^{18} \mathrm{~W} / \mathrm{cm}^{2}$, pulse duration $\tau=1.5 \times 10^{-12} \mathrm{~s}$, and wavelength $\lambda=1.054 \mu \mathrm{m}$. To compare our results with targets usually employed (to produce intense proton beams), we also used $35 \mu \mathrm{m}$-thick film targets of polyethylene.

The primary charged particle component emitted on laser shots with both $\operatorname{Ti}\left(\operatorname{TiD}_{x}\right)$ and polyethylene targets was found to be protons (deuterons) with energies $E_{\mathrm{p}} \leq 1.0 \mathrm{MeV}\left(N_{\mathrm{p}} \sim 10^{11} /\right.$ pulse). A heavy ion component (with mass $A>4$ ) was also detected. Besides these species during the shots on $\mathrm{Ti}$ and $\mathrm{TiD}_{x}$ targets, we also found energetic alpha particles that were not detected in experiments with polyethylene (Fig. 19). As can be seen, the laser shots on a titanium target produce the same tracks in the CR-39 detectors covered with $11 \mu \mathrm{m}$ of $\mathrm{Al}(d=7.2 \mu \mathrm{m})$ that were detected in electrolysis and glow discharge loading experiments. Similar shots on polyethylene target showed possible alpha emission at a level comparable with the background in the vacuum chamber of the target installation. 


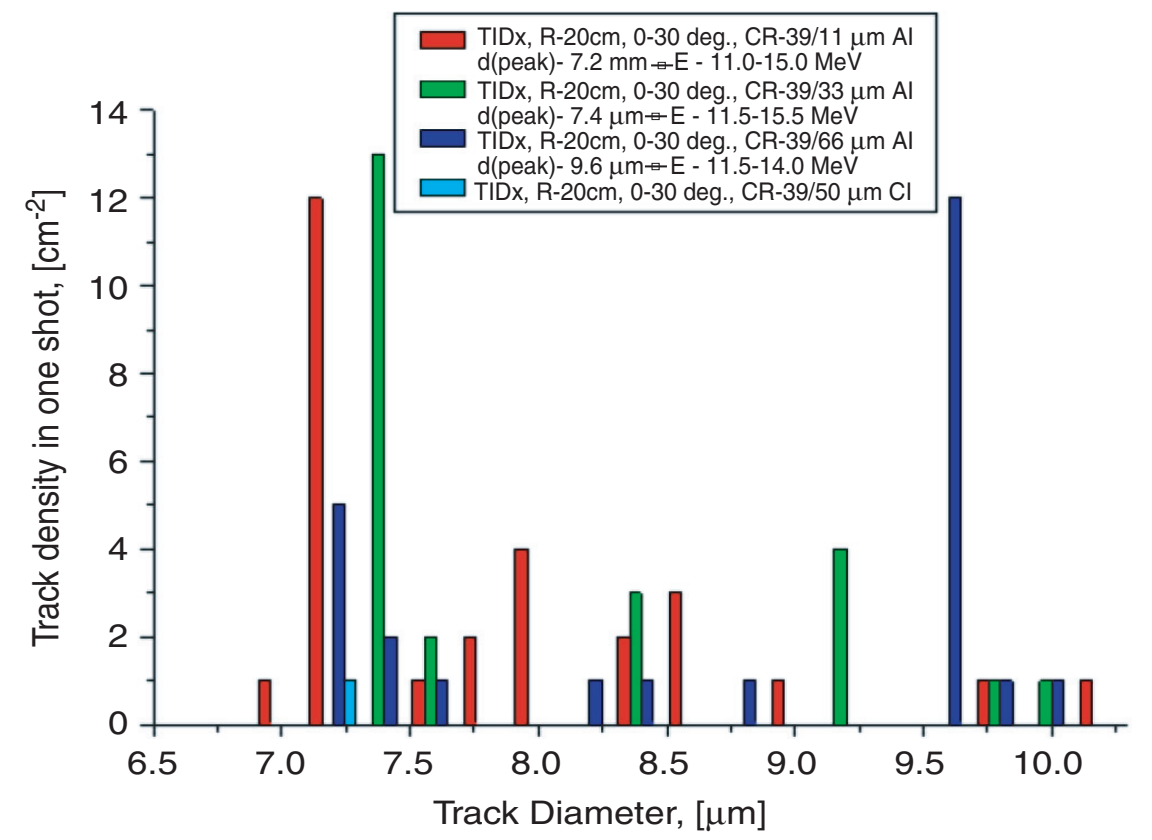

Figure 20. Track density versus track diameter detected on the front side of a $\mathrm{TiD}_{x}$ target $\left(\phi=0-30^{\circ}\right)$ in a laser experiment, using a set of CR-39 detectors covered with $11 \mu \mathrm{m} \mathrm{Al}$ foil; $33 \mu \mathrm{m} \mathrm{Al}$ foil; $66 \mu \mathrm{m} \mathrm{Al}$ foil and $50 \mu \mathrm{m} \mathrm{Cu}$ foil, respectively.

In Fig. 20, the spectra of alpha particles detected in the same laser shot by CR-39 detectors covered with various shielding and placed between 0 and $30^{\circ}$ with respect to $\mathrm{TiD}_{x}$-target are presented. The main peak in Fig. 20 corresponding to $13.0 \pm 2.0 \mathrm{MeV}$ alphas is shifted to larger track diameters for the 33 and $66 \mu \mathrm{m} \mathrm{Al}$ shielded detectors, in accordance with the $13 \mathrm{MeV}$ alpha stopping range in $\mathrm{Al}$. For the $50 \mu \mathrm{m} \mathrm{Cu}$ covered detector, this peak completely disappeared, since a $50 \mu \mathrm{m}$ thick $\mathrm{Cu}$ shielding will stop all alpha particles with energy $E \leq 15.0 \mathrm{MeV}$.

The same energy alpha particle emission, but with about 30 times less intensity, was detected from the opposite side of $\mathrm{Ti} / \mathrm{TiD}_{x}$ target (the angle between detector and target is $\varphi=180^{\circ}$ ) (Fig. 21). Here, as in Fig. 20, a track diameter corresponding to an alpha peak $(d=9.9 \mu \mathrm{m})$ is also in good agreement with the stopping range of $13.0 \mathrm{MeV} \alpha$ 's in a sandwich consisting of $\mathrm{Cu}$ shielding and Ti foil $[25 \mu \mathrm{m} \mathrm{Cu}$ (shielding) $+30 \mu \mathrm{m} \mathrm{Ti(sample} \mathrm{thickness)].} \mathrm{This} \mathrm{fact} \mathrm{allows} \mathrm{us} \mathrm{to} \mathrm{assume}$ that the alphas originated mainly at the front side of the Ti target. The estimated average intensities of alpha emission from the front, and opposite, sides of $\mathrm{Ti} / \mathrm{TiD} x$ targets (taking into account geometrical efficiency of measurement) was found to be $I_{\mathrm{f}} \sim 2 \times 10^{4} /$ pulse sr $^{-1}$ and $I_{\mathrm{r}} \sim 7 \times 10^{2} /$ pulse sr $^{-1}$, respectively.

The results of alpha spectra reconstruction from CR-39 data obtained for various shielding type and thickness (taking into account cyclotron calibration) are presented in Fig. 22. The results of such reconstruction for $\mathrm{Ti}$ and $\mathrm{TiD}_{x}$ targets are close one to another within experimental error. In Fig. 23 we show a comparison of 


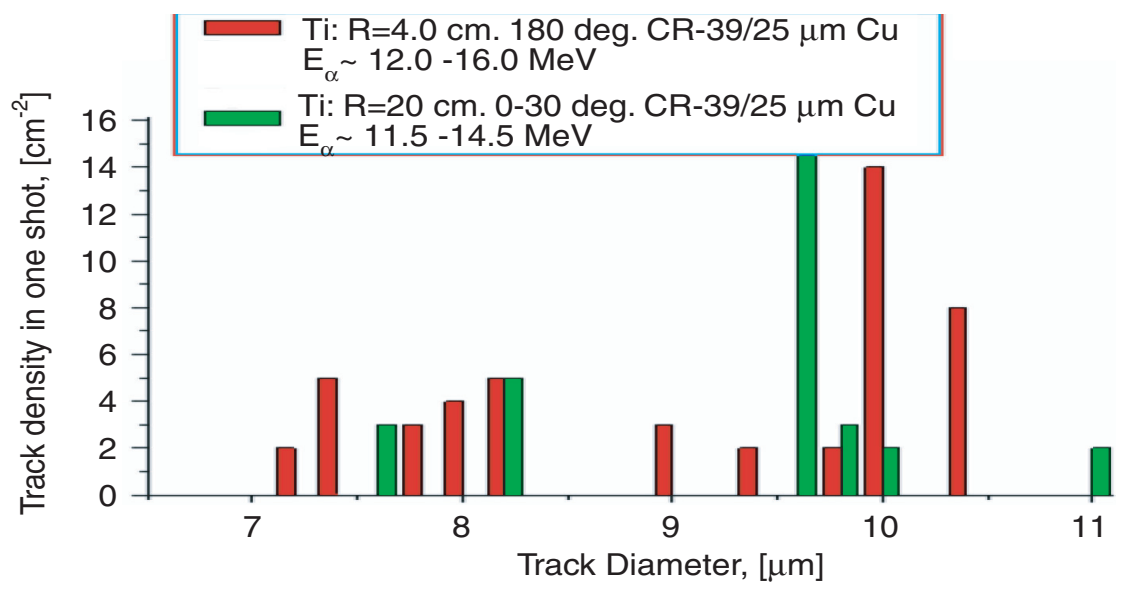

Figure 21. Track density versus track diameter detected from the front, and opposite, sides of a Ti target simultaneously in a laser experiment. The CR-39 track detectors were shielded with 25 $\mu \mathrm{m} \mathrm{Cu}$ foil.

alpha spectra obtained from a laser experiment with a titanium target, and from electrolysis with a Pd-glass sample. As seen in Fig. 23, the spectra of the laser experiment and the electrolysis experiment look quite similar within the measurement error (determined by standard deviations of alpha calibrations and errors of track diameter measurements), and both exhibit a spread in the energy range of $10-17 \mathrm{MeV}$.

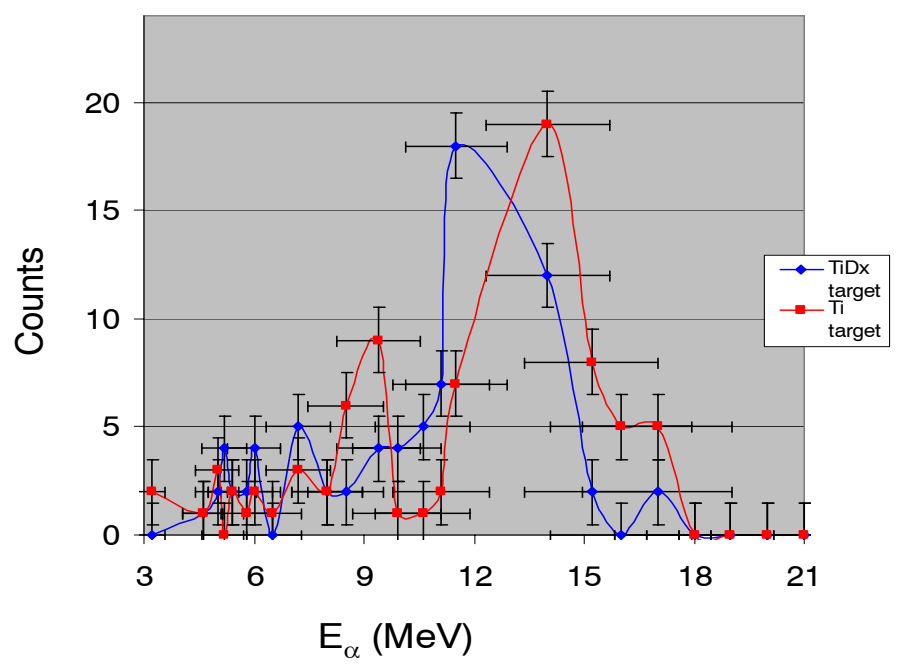

Figure 22. Reconstructed alpha spectra based on the data obtained with CR-39 track detectors shielded by $\mathrm{Al}$ and $\mathrm{Cu}$ foils in laser experiments with $\mathrm{Ti}$ and $\mathrm{TiD}_{x}$ targets. 


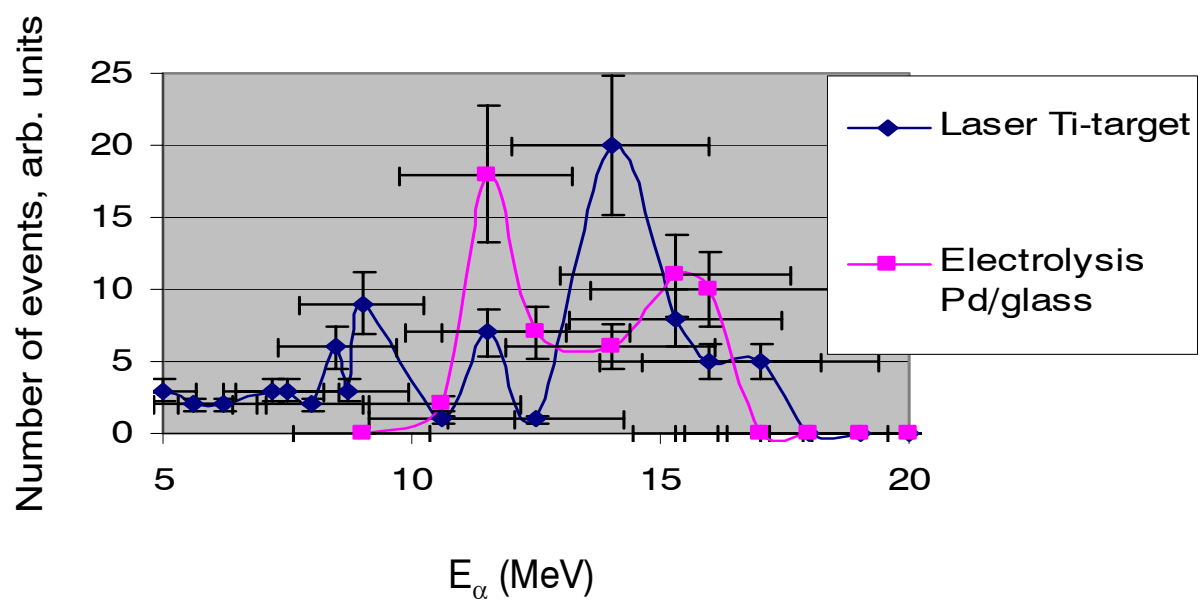

Figure 23. Comparison of CR-39 alpha spectrum in laser experiment with Ti target [deduced from Pd/glass cathode electrolysis data (Fig. 8a)].

\section{Discussion and Conclusions}

In three independent studies of energetic charged particle emission during hydrogen(deuterium) loading of $\mathrm{Pd}$ and $\mathrm{Ti}$ targets or excitation of their hydrides/deuterides, similar energetic alpha particles and protons/deuterons are found to be emitted, despite the seemingly dissimilar loading/excitation techniques. We found that the absolute intensity of energetic charged particle emission is roughly proportional (see Fig. 24) to the specific power applied to the metal target during

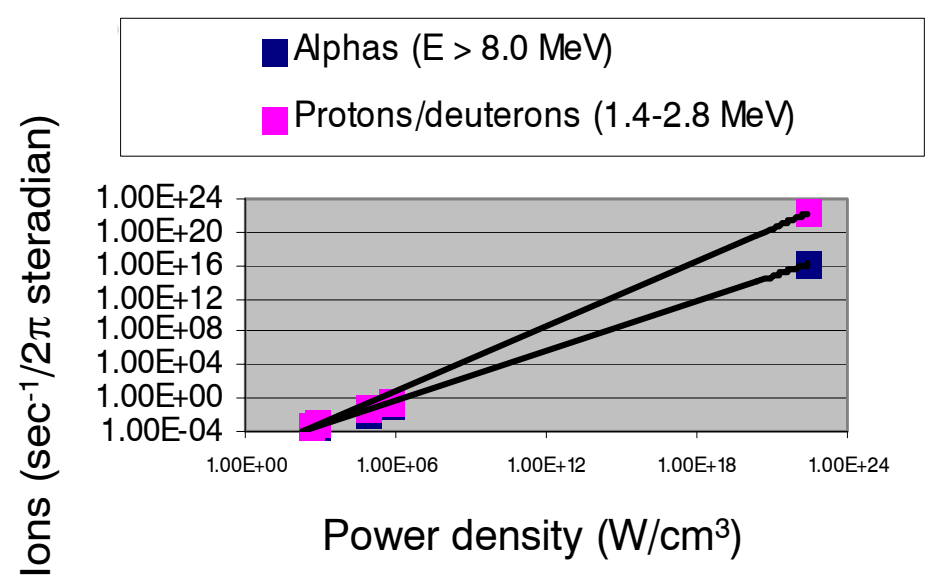

Figure 24. Yields of energetic charged particles including alphas and protons/deuterons vs. power density applied to the $\mathrm{Pd} / \mathrm{Ti}$ target in electrolysis, glow discharge and laser experiments. 


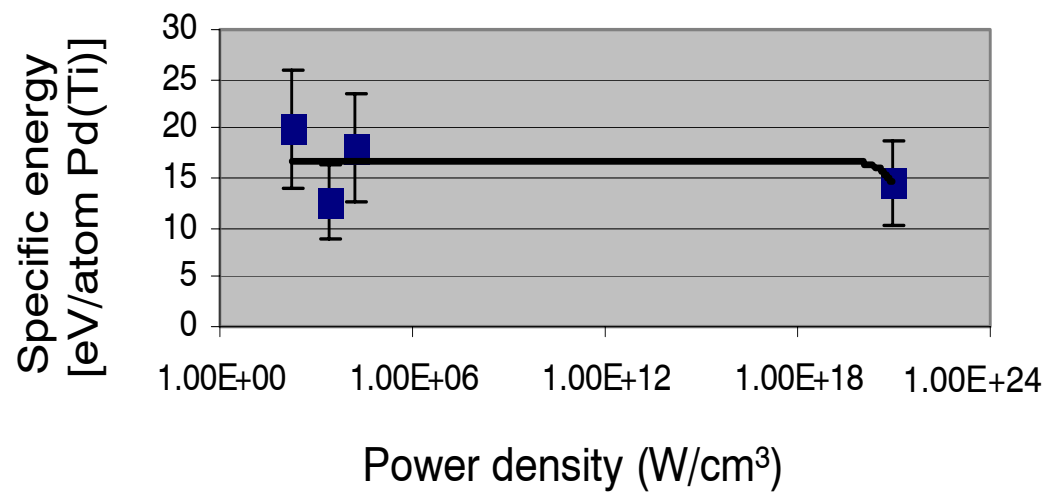

Figure 25. Specific energy required to emit energetic alpha particle $(E>8.0 \mathrm{MeV})$ vs. specific power of excitation taken with respect to the target volume. The data are taken from the electrolysis, glow discharge and laser experiments.

its loading or excitation. There are three different power density areas corresponding to the studied ranges of specific power applied in experiments on energetic charged particle emission with hydrogen/deuterium loading/excitation of $\mathrm{Ti}$ and $\mathrm{Pd}$ : electrolysis $\left((2-6) \times 10^{2} \mathrm{~W} / \mathrm{cm}^{3}\right)$; glow discharge $\left(10^{5}-10^{6} \mathrm{~W} / \mathrm{cm}^{3}\right)$, and laser irradiation $\left(\sim 10^{22} \mathrm{~W} / \mathrm{cm}^{3}\right)$. All are presented in this graph. On the other hand, the specific energy required to emit one alpha particle $(E>8.0 \mathrm{MeV})$ in all of these loading/excitation cases was found to be $E_{\mathrm{s}}=17 \pm 8 \mathrm{eV} /$ atom of $\mathrm{Ti}(\mathrm{Pd})$, and practically independent of excitation power applied to the target (Fig. 25).

That metals with large hydrogen affinity can emit energetic charged particles is probably due to peculiarities of these metals. On the one hand, metals such as $\mathrm{Pd}$ and Ti are subjected to strong plastic deformation accompanied by massive generation of non-equilibrium phonons during hydrogen loading. On the other hand, metals with a large hydrogen affinity may capture a large amount of helium (from the surrounding atmosphere or during the loading along with hydrogen), which tends to segregate in sites of high internal strain. We assume that the loading or excitation procedure produces nonequilibrium phonons in the near-surface layer of $\mathrm{Pd}$ or $\mathrm{Ti}$. These phonons would be focused (concentrated) at specific sites with high internal strain near the surface. If a mechanism for energy transfer from the concentrated optical phonon modes (with high amplitude and frequency) to the atoms captured in the sites with high internal strain really exists, ${ }^{10}$ then such energy transfer can lead to effective acceleration of the light atoms captured in the sites of high internal strain (hydrogen, deuterium helium).

Regardless of the mechanism involved in the energetic charged particle emission phenomenon in $\mathrm{Pd}$ and $\mathrm{Ti}$, we emphasize that some peculiarities of LENR could be clearer, taking into account similarities between processes observed in electrolytic loading of these metals (LENR effects) and powerful laser irradiation effects. These similarities include: 
- Neutron spectra for deuterated targets in laser and LENR experiments: besides the $2.45 \mathrm{MeV}$ peak, high energy neutrons up to $10 \mathrm{MeV}$ [compare Refs.: P.A. Norreys et al., Plasma Phys. Control. Fusion 40, 175 (1998) and 5]. The high energy component of the neutron spectra in the laser case is explained by the presence of $\mathrm{MeV}$ deuterons (there probably is a similar effect in LENR case).

- Charged particle emission, including energy ranges.

- Isotope separation and exotic transmutations.

- Production of craters at the target surface.

- Possible generation of isomeric states of nuclei in solids (subsequent emission of gammas and x-rays).

\section{References}

1. F. E. Cecil, D. Ferg, H. Liu et al., Nucl. Phys. A 539, 75 (1992).

2. R. Taniguchi, Trans. Fusion Tech. 26(4T), 186 (1994).

3. J. Kasagi, T. Ohtsuki, K. Ishu and M. Hiraga, J. Phys. Soc. Jpn. 64, 777 (1995).

4. A. Takahashi, K. Maruta, K. Ochiai and H. Miyamaru, Fusion Tech. 34, 256 (1998).

5. A.G. Lipson, B.F. Lyakhov, A.S. Roussetski et al., Fusion Tech. 38, 238 (2000).

6. A.G. Lipson, A.S. Roussetski, A. Takahashi and J. Kasagi, Bull. Lebedev Phys. Inst. 10, 22 (2001).

7. A.G. Lipson, A.S. Roussetski and G.H. Miley, Trans. Am. Nucl. Soc. 88, 638 (2003).

8. A.S. Roussetski et al., in this Proceedings.

9. K.W. Ledingham, P. McKenna and R.P. Singhal, Science 300, 1107 (2003).

10. P.L. Hagelstein, in Proceedings of the ICCF-9 on Anomalies in Metal Deuterides, Beijing, May 2002. 